\title{
ANTIBACTERIAL PROPERTIES AND CHEMICAL CHARACTERIZATION OF THE ESSENTIAL OILS FROM SUMMER SAVORY EXTRACTED BY MICROWAVE-ASSISTED HYDRODISTILLATION
}

\author{
Shila Rezvanpanah, Karamatollah Rezaei*, Mohammad-Taghi Golmakani, Seyyed Hadi Razavi
}

Department of Food Science, Engineering and Technology, University of Tehran, Karaj, Iran, Postal Code: $31587-77871$.

Submitted: October 30, 2009; Approved: May 23, 2011.

\begin{abstract}
Antibacterial properties and chemical characterization of the essential oils from summer savory (Satureja hortensis) extracted by microwave-assisted hydrodistillation (MAHD) were compared with those of the essential oils extracted using the traditional hydrodistillation (HD) method. While MAHD at $660 \mathrm{~W}$ required half as much time as HD needed, similar antibacterial efficacies were found from the essential oils obtained by the two extraction methods on two food pathogens (Staphylococcus aureus, a gram positive bacterium, and Escherchia coli, a gram negative bacterium). Also, as it was the case with the essential oils extracted by HD, that of MAHD indicated greater influence on $S$. aureus than on E. coli. The compositions of the extracted essential oils were also studied using GC-MS analysis. The same components with negligible differences in their quantities were found in the extracted essential oils using the two methods outlined above. Overall, to reduce the extraction time, MAHD can be applied at higher microwave levels without any compromise in the antibacterial properties of the essential oils extracted.
\end{abstract}

Key words: Carvacrol; Flavor and fragrance; Medicinal plant/herb; Pathogens; Scanning electron microscopy (SEM); Summer savory

\section{INTRODUCTION}

Essential oils, which are the secondary metabolites produced within the various tissues of medicinal plants/herbs, are complex mixtures of volatile compounds such as terpenes (mostly monoterpenes and sesquiterpenes), phenolics and alcohols (17). It has been found that essential oils from spices, medicinal plants/herbs can possess certain levels of antimicrobial activities and as a result they can also be considered as potential antimicrobial agents against food pathogens (7). Satureja hortensis L., known as summer savory, from Labiatae family has been traditionally used as a stimulant, stomachic, carminative, expectorant, antidiarrheic, and aphrodisiac herb (23). Various biologically-active constituents from triterpene and flavonoid categories consisting of many components such as carvacrol, thymol, $\delta$-terpinene, $\rho$-cymene, and $\alpha$ - and $\beta$-pinene (20) have been found in summer savory. Carvacrol, which is a major component of savory essential oils with a concentration of $25-50 \mathrm{~g} \mathrm{~kg}^{-1}(20,22)$, has been known as a growth inhibitor against different bacteria and fungi (20, 22). Effectiveness of the essential oils in preventing the growth of bacteria encourages research on the extraction of these oils

*Corresponding Author. Mailing address: Department of Food Science, Engineering and Technology, University of Tehran, Karaj, Iran, Postal Code: $31587-$ 77871.; Tel.: (+98) 261-2235124 Fax: (+98) 261-2248104.; E-mail: krezaee@ut.ac.ir 
from the medicinal plants and investigations on their antibacterial activities.

The conventional method for the extraction of essential oils is hydrodistillation (HD), in which the essential oils are evaporated by heating a mixture of water and plant materials followed by the liquefaction of the vapors in a condenser. Reportedly, this method suffers from several disadvantages including losses in the volatile compounds, long extraction time and degradation of some components through thermal and/or hydrolytic effects $(14,17)$. Among the newly developed extraction methods, microwave-assisted hydrodistillation (MAHD) has been used in the extraction of volatile secondary metabolites from various plant sources. Compared to the traditional HD, MAHD is faster extraction technique providing a higher energy level at a shorter extraction time in a more uniform way within the sample. In a previous study (21), extraction kinetics and extraction efficiency of essential oils from summer savory were compared against those of winter savory. Summer savory indicated greater oil content when compared to winter savory $(3.1 \%$ vs. $0.7 \%$, respectively). No studies were found in the literature to compare these two methods in the extraction of essential oils from summer savory. Therefore, the objectives of this study were to focus only on summer savory and to quantitatively compare the components in the extracted essential oils when using MAHD and HD as extraction methods. Also, possible differences in the antibacterial activities of the extracted essential oils against a Gram-positive bacterium, Staphylococcus aureus, and a Gramnegative bacterium, Escherchia coli, were investigated.

\section{MATERIALS AND METHODS}

\section{Plant materials}

Dried aerial parts of $S$. hortensis were provided by Industrial Center for Plant Pesticides and Fertilizers (Karaj, Iran) with a moisture content of $9.0 \%$. The plant (dried aerial parts) was identified in the Herbarium Section of the University of Tehran (Dr. Gholamreza Amin, Head of
Herbarium, Faculty of Pharmacy, Tehran University of Medical Sciences, Tehran, Iran). The voucher number assigned for the species used in this study is PMP-402.

\section{Hydrodistillation}

Thirty g of dried S. hortensis along with $600 \mathrm{~mL}$ distilled water was subjected to HD for $4 \mathrm{~h}$ using a Clevenger-type apparatus. The essential oils obtained this way was separated from water (due to its immiscibility with water and also as a result of a difference in its density level) and then dried over anhydrous sodium sulfate and stored in vials at $4{ }^{\circ} \mathrm{C}$. The extraction was repeated 3 times.

\section{Microwave-assisted hydrodistillation}

A household microwave oven (model NN-S674 MF, Panasonic Corp., Japan), at $2.45 \mathrm{GHz}$ frequency (according to the manufacturer's datasheet for that specific oven) with a maximum output power of $1100 \mathrm{~W}$ and inner dimensions of $22.5 \mathrm{~cm} \times 37.5 \mathrm{~cm} \times 38.6 \mathrm{~cm}$ equipped with a flask and a condenser was used for MAHD. Thirty $g$ of dried herb with $600 \mathrm{~mL}$ distilled water were placed in a $2 \mathrm{~L}$ flask and MAHD was performed at three different power levels of 220, 440 and $660 \mathrm{~W}$. The heating efficiency of microwave oven at each power level was determined by measuring temperature changes with similar amount of water in the microwave oven. The essential oils were removed from the apparatus, dried over anhydrous sodium sulfate and stored at $4{ }^{\circ} \mathrm{C}$ until used. Full safety precautions including the use of personal protective equipment are needed when working with the microwave radiation as they can be harmful for different organs of human body once directly exposed to such radiation. Such measures were considered in the current study by placing the microwave oven inside a fume hood fully covered by aluminum foil.

\section{Gas chromatography-mass spectrometry}

A Gas Chromatography-Mass Spectrometry (GC-MS) instrument (5973N, Agilent Technologies, Wilmington, DE) equipped with a mass selective detector operating in the 
electron impact mode $(70 \mathrm{eV})$ was used to study the compositions of the extracted essential oils. The GC part (6890N, Agilent Technologies, Palo Alto, CA) was equipped with an HP-5MS (Agilent Technologies) capillary column (30 $\mathrm{m}$ long, $0.25 \mathrm{~mm}$ id and $0.25 \mu \mathrm{m}$ film thickness). Temperature programming of the oven included an initial hold at $50{ }^{\circ} \mathrm{C}$ for 5 min and a rise to $240{ }^{\circ} \mathrm{C}$ at $3{ }^{\circ} \mathrm{C} \min ^{-1}$ followed by additional rise to $300{ }^{\circ} \mathrm{C}$ at $5{ }^{\circ} \mathrm{C} \mathrm{min}{ }^{-1}$. A final hold for $3 \mathrm{~min}$ was allowed for a complete column clean-up. The injector was set at 290 ${ }^{\circ} \mathrm{C}$. One $\mu \mathrm{L}$ of each sample was injected to the GC with the injector in the split mode (split ratio: 1/10). Carrier gas, He, was adjusted to a linear velocity of $0.8 \mathrm{~mL} \mathrm{~min}^{-1}$. The compounds of the extracted essential oils were identified by comparing their mass spectral fragmentation patterns with those of the same compounds from a database (Wiley/NBS library) as well as by comparing their gas chromatographic retention indices (relative to the retention times of $n$-alkanes) with those of the literature.

\section{Preparation of bacterial strains}

The bacterial strains used as test microorganisms were $E$. coli PTCC 1399 and S. aureus PTCC 1431 obtained from Persian Type Culture Collection (Tehran, Iran). The bacterial cultures were grown on the nutrient agar slant purchased from Merck (Merck, Darmstadt, Germany) and maintained at $4{ }^{\circ} \mathrm{C}$ until they were used. Subculturing was carried out on a monthly basis in order to maintain bacterial activity. For each test, working cultures were prepared by subculturing each stock culture in the nutrient broth and incubated at $37^{\circ} \mathrm{C}$ for 24 $\mathrm{h}$ to allow the growing of the microorganism. Using sterile distilled water, serial dilutions were carried out to obtain a bacterial population of $10^{6}-10^{7} \mathrm{CFU} / \mathrm{mL}$ using the standard procedure of PCA (2).

\section{Determination of antibacterial activity}

The antibacterial activities of the essential oils were determined according to the disc diffusion method used by
Kim et al. (15). The Petri dishes containing Brain Heart Agar (BHA) medium (Merck, Darmstadt, Germany) were used for such purpose. One $\mathrm{mL}$ of overnight $S$. aureus and E. coli broth cultures were separately spread on each plate containing BHA by surface culturing method by which the microorganism broth cultures were added to the plate of BHA and spread on the plate by sterile glass bar. Solutions for the essential oils were prepared in absolute ethanol (Merck, Darmstadt, Germany) at $1: 5,1: 10,1: 50,1: 100$ and 1:150 dilution levels. Sterile filterpaper discs (Watman No. 1, $6 \mathrm{~mm}$ in diameter) were impregnated with essential oil extracts. The soaked discs were then placed on the center of inoculated agar surfaces. Control disks were impregnated with ethanol alone. All the plates were incubated at $37^{\circ} \mathrm{C}$ for $24 \mathrm{~h}$. Diameters (in mm) of the bacterial inhibition zones minus the disc diameter were used to evaluate the inhibition effect of essential oils. Triplicate experiments were performed for each concentration of the essential oils. Statistical analysis was done using SAS software v6.12 (SAS Institute Inc., Cary, NC) considering LSD means for regression analysis.

\section{Scanning electron microscopy (SEM)}

SEM images of dried savory leaves were obtained for the untreated samples as well as for those samples undergone MAHD at $660 \mathrm{~W}$ power level (for $2 \mathrm{~h}$ ) and HD (for $4 \mathrm{~h}$ ). The leaves were fixed on the specimen holder with aluminum tape and then sputtered with gold in a sputter coater (Type SCD 005, Bal-Tec Inc., Balzers, Switzerland). All the specimens were examined with a scanning electron microscope (XL Series, model XL30, Philips, Eindhoven, The Netherlands) under high vacuum condition and at an accelerating voltage of $20.0 \mathrm{kV}$.

\section{RESULTS AND DISCUSSION}

\section{Extraction yield}

Data showing the lengths of times needed by MAHD and HD to reach the extraction temperature (so-called induction 
times) and those indicating the total recoveries of essential oils at different power levels were published elsewhere (21). For MAHD at $660 \mathrm{~W}$, the extraction started much earlier than that for HD. However, with the microwave power reduced to 220 $\mathrm{W}$, the induction time with MAHD was longer than that with HD. Both MAHD and HD resulted in the same yield $(3.1 \%$, w/w) after the full extraction of essential oils. In Fig. 1, total times needed to fully recover the essential oils from summer savory at different power levels of microwave are compared against that with the traditional HD. No more essential oils were observed beyond these times. Total extraction time needed for HD to recover all the essential oils was $240 \mathrm{~min}$.
However, MAHD needed much shorter times than did HD. When microwave power was increased to higher levels, the extraction time was also reduced accordingly. According to Chen and Spiro (6) and Lucchesi et al. (17), at higher power levels, the microwaves (i.e., the radiations) can be absorbed more intensively resulting in a shorter extraction times. Golmkani and Rezaei $(11,12)$ investigated the effect of microwaves at higher power levels on the extraction of essential oils from Thymus vulgaris L. and Zataria multiflora Bois. They found no adverse effects from the microwaves on the molecular structures of the extracted essential oils in either case.

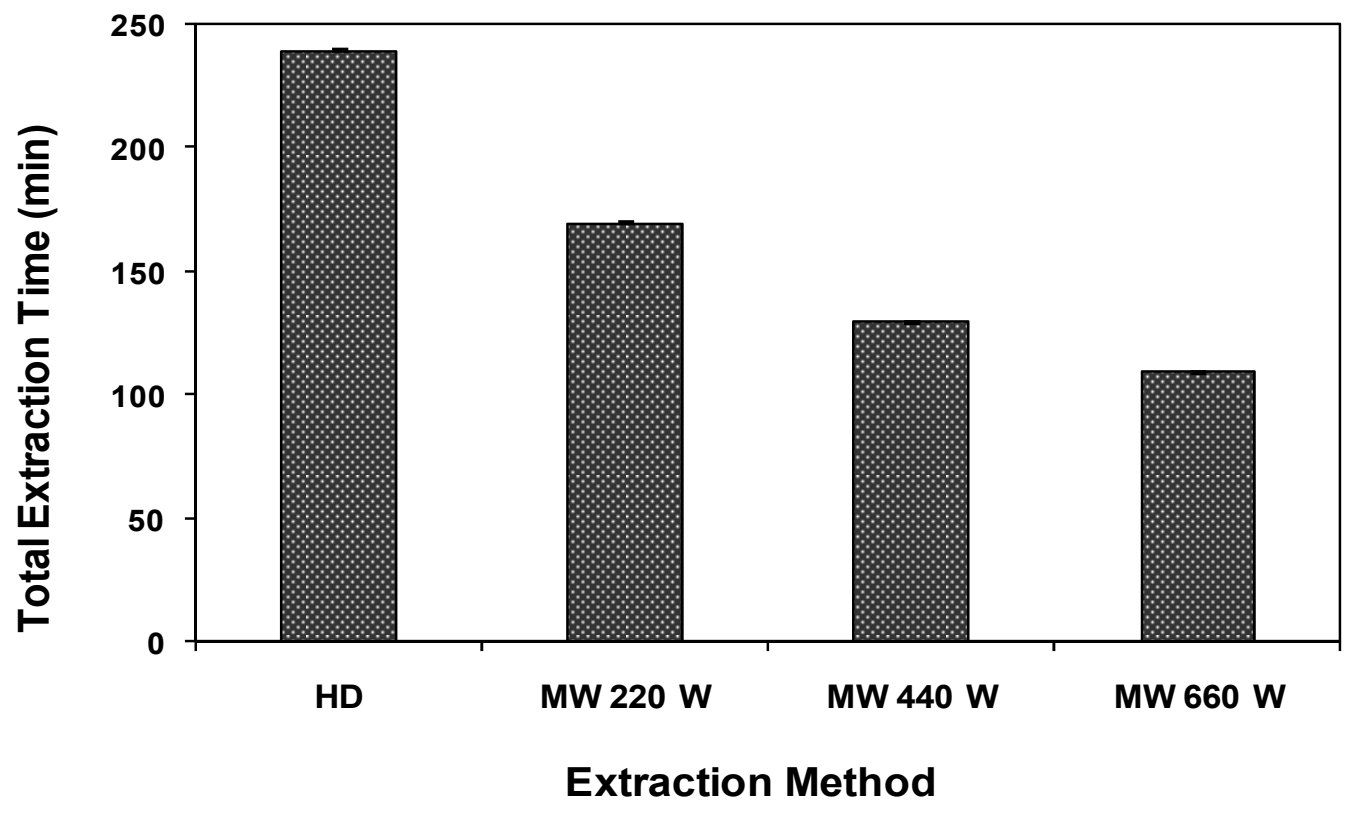

Figure 1. Comparing microwave-assisted hydrodistillation (MAHD) to the traditional hydrodistillation (HD) in the extraction of essential oils from summer savory (Satureja hortensis L.).

\section{Compositions of the essential oils}

The identified components in the essential oils extracted from the leaves of $S$. hortensis by HD and MAHD (at $660 \mathrm{~W}$ power level) are shown in Table 1. The 31 components shown here consist of $98 \%$ of total GC peak area. The composition of the essential oils extracted by HD was similar to those of essential oils obtained by MAHD. Slight differences were found in the concentration levels of compounds $6,9,10,21$ and 24 between the two extraction methods. But, the major components such as carvacrol and $\gamma$-terpinene do agree well 
between the two extraction techniques examined here. Indeed, there were no significant differences between the main components extracted by the two methods and they consist about $80 \%$ of total essential oils. The extracted essential oils in the current study were rich in the active monoterpene phenols. Carvacrol (compound 23) was the most abundant component in the savory essential oils ( $48.7 \%$ for HD and $47.7 \%$ for MAHD) followed by $\gamma$-terpinene (compound 13) as monoterpene hydrocarbon precursor for carvacrol $(32.0 \%$ for HD and $30.0 \%$ for MAHD). The compositions of the essential oils in the current study are similar to those of the essential oils extracted from $S$. hortensis by Sefidkon et al. (22) and Esquivel et al. (9) using HD and steam distillation. The plant's development stage has great influence on the composition of the essential oils (19). Although the essential oils from $S$. montana mostly consist of such phenols as thymol and carvacrol, according to Mastelic and Jerkovic (19), the highest level of thymol was identified in young plants (in
June), and the highest carvacrol level was obtained during the flowering period in September. The plant used in the current study was also collected during their flowering period in September and therefore can be expected to have greater carvacrol content accordingly. In addition, Venskutonis (28) studied the effect of drying on the volatile constituents of thyme and sage. They found that drying at $30^{\circ} \mathrm{C}$ resulted in more extraction of volatiles, but at higher temperature $\left(60^{\circ} \mathrm{C}\right)$, there was a significant reduction in the volatiles. In the current study, the plant was dried in the shadow at room temperature (around $25^{\circ} \mathrm{C}$ ) on a large screened tray and therefore according to the above study (28) greater quantities of volatiles could be obtained for such a case. The GC-mass results from the current study showed that microwaves did not involve in the deterioration or loss of volatile components when they were compared with the components obtained by the traditional HD method. Therefore, MAHD can be recommended as an alternative/safe method for the extraction of essential oils.

Table 1. Chemical compositions of the essential oils obtained by hydrodistillation (HD) and microwave-assisted hydrodistillation (MAHD, $660 \mathrm{~W}$ power level) of summer savory

\begin{tabular}{|c|c|c|c|c|c|}
\hline \multirow[b]{2}{*}{ No. } & \multirow[b]{2}{*}{$\mathrm{RT}^{\mathrm{b}}$ (min) } & \multirow[b]{2}{*}{ Compound } & \multirow[b]{2}{*}{$I_{K}^{\mathrm{c}}$} & \multicolumn{2}{|c|}{ Relative peak area $^{\mathrm{a}}(\%)$} \\
\hline & & & & HD & MAHD \\
\hline 1 & 16.83 & $\alpha$-Thujene & 944 & $1.34 \pm 0.02$ & $1.33 \pm 0.13$ \\
\hline 2 & 17.26 & $\alpha$-Pinene & 951 & $1.34 \pm 0.06$ & $1.33 \pm 0.18$ \\
\hline 3 & 18.11 & Camphene & 967 & $0.10 \pm 0.01$ & $0.11 \pm 0.00$ \\
\hline 4 & 19.46 & Sabinene & 991 & $0.03 \pm 0.00$ & $0.03 \pm 0.00$ \\
\hline 5 & 19.69 & $\beta$-Pinene & 995 & $0.72 \pm 0.01$ & $0.81 \pm 0.10$ \\
\hline 6 & 20.33 & $\beta$-Myrcene & 1007 & $1.78 \pm 0.03$ & $2.05 \pm 0.18$ \\
\hline 7 & 21.17 & $\alpha$-Phellandrene & 1022 & $0.31 \pm 0.01$ & $0.35 \pm 0.03$ \\
\hline 8 & 21.50 & $\Delta$-3-Carene & 1028 & $0.07 \pm 0.01$ & $0.08 \pm 0.01$ \\
\hline 9 & 21.88 & $\alpha$-Terpinene & 1035 & $3.89 \pm 0.12$ & $4.55 \pm 0.36$ \\
\hline 10 & 22.31 & p-Cymene & 1043 & $2.69 \pm 0.28$ & $3.55 \pm 0.62$ \\
\hline 11 & 22.53 & Limonene & 1048 & $0.61 \pm 0.07$ & $0.36 \pm 0.49$ \\
\hline 12 & 23.48 & $\beta$-Ocimene & 1065 & $0.11 \pm 0.01$ & $0.13 \pm 0.01$ \\
\hline 13 & 24.40 & $\gamma$-Terpinene & 1082 & $31.95 \pm 2.23$ & $29.99 \pm 0.50$ \\
\hline 14 & 24.68 & cis-Sabinene hydrate & 1088 & $0.38 \pm 0.11$ & $0.49 \pm 0.01$ \\
\hline 15 & 25.73 & Terpinolene & 1108 & $0.09 \pm 0.03$ & $0.12 \pm 0.00$ \\
\hline 16 & 26.28 & trans-Sabinene hydrate & 1118 & $0.22 \pm 0.07$ & $0.25 \pm 0.06$ \\
\hline 17 & 28.82 & Camphor & 1168 & $0.07 \pm 0.05$ & $0.14 \pm 0.05$ \\
\hline 18 & 29.89 & Borneol & 1189 & $0.16 \pm 0.02$ & $0.19 \pm 0.02$ \\
\hline 19 & 30.42 & Terpinene-4-ol & 1200 & $0.24 \pm 0.08$ & $0.22 \pm 0.04$ \\
\hline 20 & 31.25 & $\alpha$-Terpineol & 1217 & $0.07 \pm 0.01$ & $0.07 \pm 0.03$ \\
\hline 21 & 33.48 & Carvacrol methyl ether & 1264 & $0.04 \pm 0.00$ & $0.06 \pm 0.00$ \\
\hline 22 & 35.81 & Thymol & 1313 & $1.11 \pm 0.20$ & $1.24 \pm 0.12$ \\
\hline 23 & 36.74 & Carvacrol & 1334 & $48.69 \pm 1.50$ & $47.74 \pm 1.35$ \\
\hline 24 & 39.47 & Carvacryl acetate & 1394 & $0.48 \pm 0.03$ & $0.66 \pm 0.09$ \\
\hline 25 & 41.89 & $\beta$-Caryophyllene & 1451 & $0.71 \pm 0.09$ & $0.71 \pm 0.03$ \\
\hline 26 & 42.77 & Aromadendrene & 1472 & $0.04 \pm 0.02$ & $0.04 \pm 0.00$ \\
\hline 27 & 43.40 & $\alpha$-Humulen & 1486 & $0.04 \pm 0.01$ & $0.04 \pm 0.01$ \\
\hline 28 & 45.34 & $\beta$-Bisabolene & 1534 & $0.53 \pm 0.10$ & $0.52 \pm 0.04$ \\
\hline 29 & 46.67 & cis- $\alpha$-Bisabolene & 1567 & $0.06 \pm 0.01$ & $0.07 \pm 0.01$ \\
\hline 30 & 48.49 & Spathulenol & 1613 & $0.10 \pm 0.01$ & $0.11 \pm 0.01$ \\
\hline 31 & 48.78 & Caryophyllene oxide & 1621 & $0.12 \pm 0.06$ & $0.14 \pm 0.02$ \\
\hline \multicolumn{4}{|c|}{ Total peak area $(\%)$} & $98.10 \pm 0.48$ & $97.50 \pm 0.71$ \\
\hline \multicolumn{4}{|c|}{ Total extraction time $(\mathrm{h})$} & 2.0 & 4.0 \\
\hline
\end{tabular}

${ }^{\mathrm{b}}$ Retention Time

${ }^{c}$ Kováts Retention Index $\left(I_{K}\right)$ relative to $\mathrm{C}_{9}-\mathrm{C}_{17} n$-alkanes on the HP-5MS column. 


\section{Structural image analysis of the leaves after the extraction}

In order to investigate the changes in the cell during each extraction method, savory leaves were examined using a scanning electron microscope. Fig. $2 \mathrm{a}$ is a micrograph of the untreated leaf, which can be compared with those of the samples undergone $4 \mathrm{~h}$ of HD (Fig. 2b) and $2 \mathrm{~h}$ of MAHD at $660 \mathrm{~W}$ (Fig. 2c). The treated leaves indicated substantial differences compared to those untreated. Both HD and MAHD caused the burst of the glands and as a result the oil diffusion to the medium. These results are in good agreement with those of Golmakani and Rezaei $(11,12)$ in the extraction of essential oils from Thymus vulgaris L. and Zataria multiflora Boiss. using MAHD and HD as extraction techniques. They compared the micrographs of leaves undergone $30 \mathrm{~min}$ of MAHD with those from $60 \mathrm{~min}$ HD. According to their results, while MAHD caused the rupture of the glands in $30 \mathrm{~min}$, HD did not show any changes during that period. A longer period, however, caused the wrinkling of the gland cell walls with HD. Such difference between the results of HD and MAHD can be related to the differences in the rates of heat exchange in the two methods. Compared to HD, MAHD utilizes more ways of heat transfer (to heat up the samples).

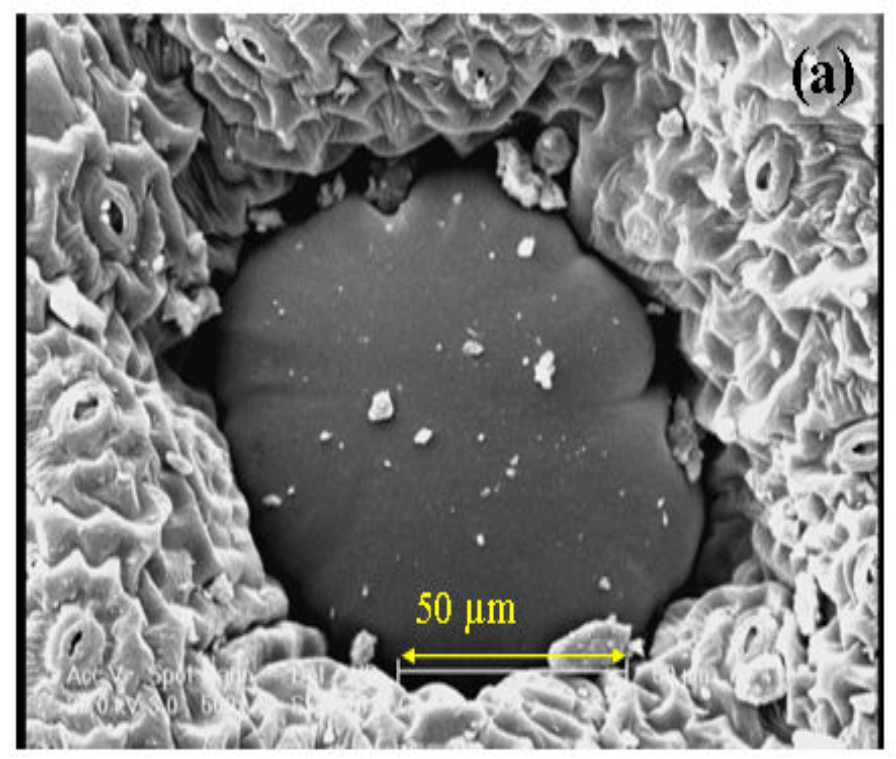

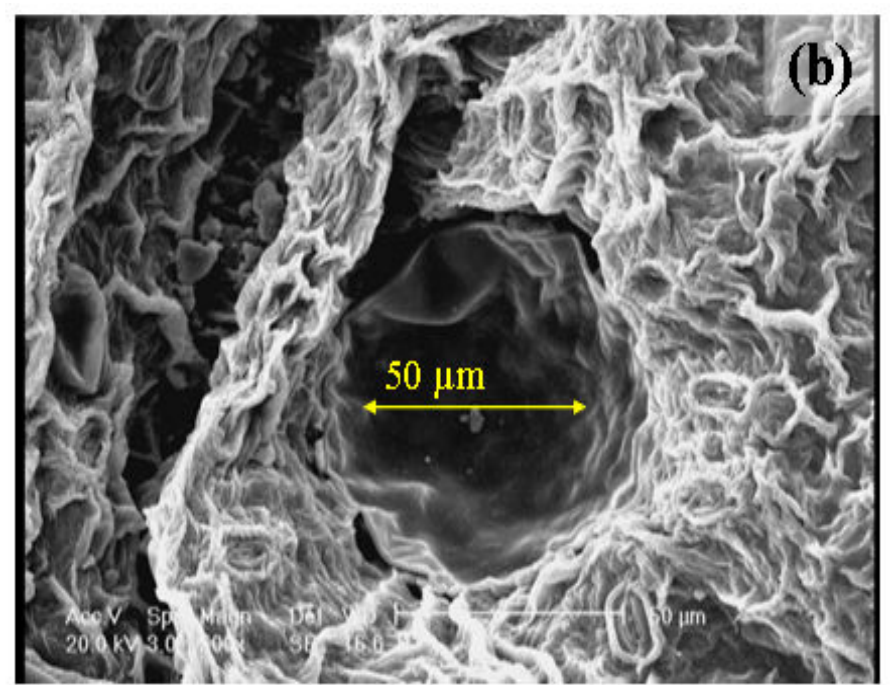

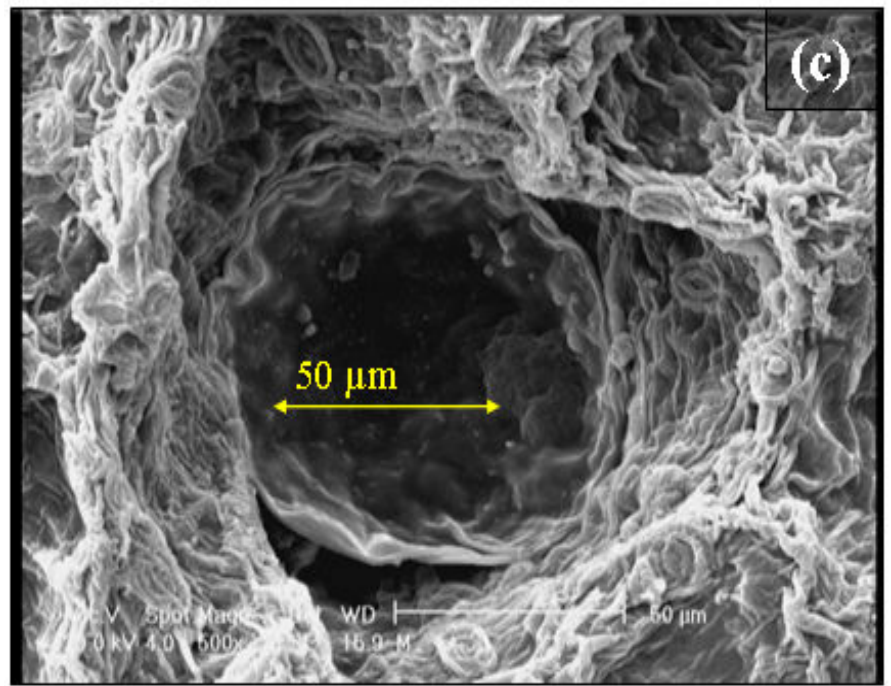

Figure 2. Scanning electron micrographs (originally taken at 500 magnification level) of the glands from summer savory leaves: (a) untreated, (b) after hydrodistillation for $4 \mathrm{~h}$ and (c) after microwave-assisted hydrodistillation (at $660 \mathrm{~W}$ power level) for $2 \mathrm{~h}$.

\section{Antibacterial activities of the extracted essential oils}

Antibacterial effects of essential oils from summer savory (extracted by HD and MAHD) at different concentration levels using $E$. coli and $S$. aureus as food pathogens are shown in Fig. $3 \mathrm{a}$ and $3 \mathrm{~b}$, respectively. Similar antibacterial activities were found for the essential oils (at all dilution levels) of summer savory extracted by HD and MAHD at three different power 
levels. Therefore, MAHD as a fast extraction technique did not have any adverse effect on the antibacterial activity of the extracted essential oils from summer savory. This finding is consistent with the GC-mass data obtained for the extracted essential oils (previous section). The essential oils extracted by HD and MAHD containing the same components (especially carvacrol as a phenolic compound) at similar levels resulted in similar antibacterial efficacies.

Considering the effect of dilution level of the essential oils, those at higher concentration levels, for example at 1:5 and 1:10 dilutions, indicated greater antibacterial efficacies due to the higher concentrations of antibacterial constituents present in the essential oils. By reducing the concentration of essential oils, the antibacterial efficacy was also decreased. While studying the antimicrobial effects of essential oils from various onions and garlic, Bendahou et al. (2) also showed that higher concentrations of oils were more effective on such microorganisms as $S$. aureus and Salmonella enteritidis. Control treatment (ethanol alone) in the current study did not indicate any inhibitory effect on any of the pathogens studied here. A possible relationship between the chemical structure of the components in the essential oils and their antimicrobial activities has been reported $(8,10)$. Essential oils rich in such phenolic compounds as carvacrol were reported to possess high levels of antimicrobial activities $(1,13,24)$. According to the findings of Marino et al. (18), oregano, rosemary, thyme and sage are among the herbs having high concentrations of phenolic compounds. For example, Origanum glandulosum from Labiatae family consists of many phenolic compounds such as thymol, carvacrol, carvacrol methyl ether and its precursors $\rho$-cymene and $\gamma$-terpinene, all of which provide microbiological safety in foods (3). Comparing the diameters of the inhibition zones from $S$. aureus and E. coli at the same concentration levels of essential oils showed that the Gramnegative bacterium, E. coli, was significantly more resistant $(p<0.05)$ to the essential oils from summer savory than was the
Gram-positive bacterium, S. aureus. This can be related to the greater complexity of the double-membrane cell envelope of Gram-negative microorganisms compared to the singlemembrane glycoprotein/techoic acid of the Gram-positive bacterium $S$. aureus $(16,27,29)$. Our results are in agreement with the findings of Skocibusic et al. (25), who investigated the inhibitory effects of essential oils of Satureja subspicata from Croatia on several Gram-positive bacteria such as Bacillus subtilis, Listeria monocytogenes and several Gram-negative bacteria such as Aeromonas hydrophila and Salmonella typhimurium. Skocibusic et al. (25) reported that the Grampositive bacteria were more susceptible to the essential oils obtained from the above sources. The mechanism of antimicrobial effect of essential oils is explained by alerting the structure and function of cytoplasmic membrane, which is accompanied by the efflux of cytoplasmic constituents including ATP in the target microorganisms (16). According to the findings of Busatta et al. (5), terpinene-4-ol, the major component of marjoram, causes the membrane deformation and consequent changes in the membrane permeability. Essential oils having hydrophobic properties can penetrate into the cell membrane of bacteria, dissolve in the membrane and as a consequence reduce its function by changing the ion transportation pattern and enzyme inactivation (4). In general, essential oils possess their antimicrobial properties by interfering and destabilizing the performance of phospholipid biolayer of the cell membrane, enzyme activities and genetic resources in the bacteria (26).

Our results proved the antibacterial activities of essential oils from summer savory against two popular food pathogens, E. coli and $S$. aureus. Furthermore, use of microwave irradiation in MAHD for the extraction of essential oils did not disturb such activities. Therefore, essential oils obtained by such method can be used in many foods as natural preservatives as are the cases with the use of marjoram essential oils in sausage and thyme essential oils for beef (26). 


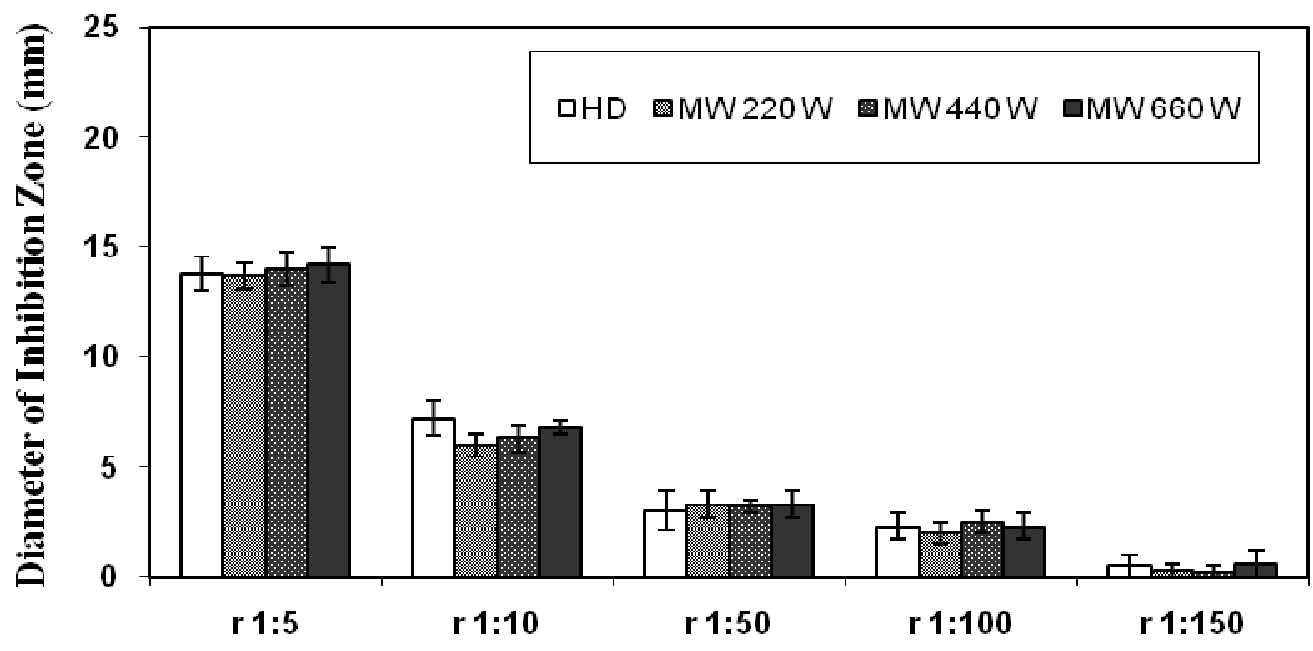

(a)

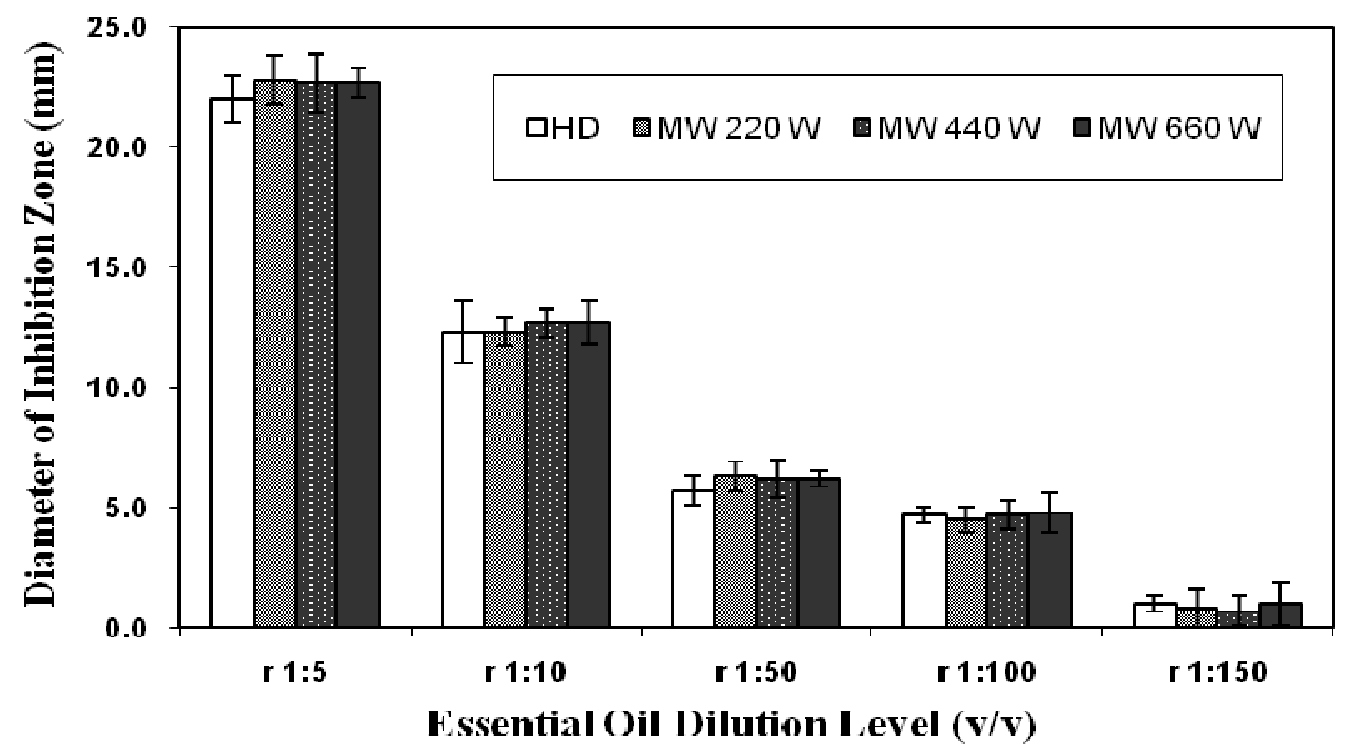

(b)

Figure 3. Antibacterial effects of different concentrations of essential oils from summer savory against two pathogens (a) the Gram-negative bacterium E. coli. (b) the Gram-positive bacterium S. aureus. (r indicates the ratio of essential oils to ethanol, which was applied for dilution purposes).

\section{CONCLUSIONS}

Natural preservatives such as the essential oils extracted from the medicinal plants show great potential against bacterial activities in processed foods. The essential oils extracted from summer savory indicated antibacterial activities against $E$. coli and $S$. aureus. Therefore, other than their use as food flavors, essential oils from summer savory can be considered as an alternate preservative for reducing the bacterial activities of food products. MAHD as an alternate extraction technique to HD did not reduce the antibacterial activity of the extracted essential oils from summer savory. This was consistent with 
the $\mathrm{GC}-\mathrm{MS}$ data indicating no differences between the essential oils obtained by MAHD and that obtained by HD.

\section{ACKNOWLEDGEMENTS}

This work has been partially funded by "the Council for Research at the Campus of Agriculture and Natural Resources of the University of Tehran" and "Research Council of the University of Tehran." Gratitude is expressed to "Industrial Center for Plant Pesticides and Fertilizers (Karaj, Iran) for providing the plant materials and also for purchasing part of the equipment. The authors would like to thank Mrs. Nahal Bashiri Hashemi and Mrs. Ziba Chehrazi for their technical assistance during this project.

\section{REFERENCES}

1. Aligiannis, N.; Kalpoutzakis, E.; Mitakou, S.; Chinou, I. B. (2001) Composition and antimicrobial activity of the essential oils of two Origanum species. J. Agric. Food Chem., 49, 4168-4170.

2. Bendahou, M.; Muselli, A.; Grignon-Dubois, M.; Benyoucef, M.; Desjobert, J. M.; Benkeblia, N. (2004). Antimicrobial activity of essential oils extracts of various onions (Allium cepa) and garlic (Allium sativum). LWT-Food Sci. Technol., 37, 263-268.

3. Bendahou, M.; Muselli, A.; Grignon-Dubois, M.; Benyoucef, M.; Desjobert, J. M.; Bernardini, A. F.; Costa, J. (2008). Antimicrobial activity and chemical composition of Origanum glandulosum Desf. essential oils and extract obtained by microwave extraction: Comparison with hydrodistillation. Food Chem., 106, 132-139.

4. Burt, S. (2004). Essential oils: their antibacterial properties and potential applications in foods - a review. Int J. Food Microbiol., 94, 223-253.

5. Busatta, C.; Vidal, R. S.; Popiolski, A. S.; Mossi, A. J.; Dariva, C.; Rodrigues, MRI. R. I.; Corazza, F. C.; Corazza, M. L.; Vladimir Oliveira, J,oliveira, J.; Cansian, R. L. (2007). Application of Origanum majorana L. essential oils as an antimicrobial agent in sausage. Food Microbiol., 25, 207-211.

6. Chen, S. S.; Spiro, M. (1995). Kinetics of microwave extraction of rosemary leaves in hexane, ethanol and a hexane + ethanol mixture. Flav. Frag. J., 10, 101-112.

7. Deans, S. G.; Ritchie, G. (1987.), Antibacterial properties of plant essential oils. Int. J. Food Microbiol., 5, 165-180.

8. Deans, S. G.; Svoboda, K. P. (1990). The antimicrobial properties of marjoram (Origanum majorana L.) volatile oil. Flav. Frag. J., 5, $187-$ 190.

9. Esquivel, M. M.; Ribeiro, M. A.; Bernardo-Gil, M. G. (1999). Supercritical extraction of savory oil: study of antioxidant activity and extract characterization. J. Supercritic. Fluids, 14, 129-138.

10. Farag, R. S.; Daw, Z. Y.; Hewedi, F. M.; El-Baroty, G. S. A. (1989). Antimicrobial activity of some Egyptian spice essential oils. J. Food Protect., 52, 665-667.

11. Golmakani, M.; Rezaei, K. (2008a). Comparison of microwave-assisted hydrodistillation with the traditional hydrodistillation method in the extraction of essential oils from Thymus vulgaris L. Food Chem., 109, 925-930.

12. Golmakani, M.; Rezaei, K. (2008b). Microwave-assisted hydrodistillation of essential oils from Zataria multiflora Boiss. Europ J. Lipid Sci. Technol., 110, 448-454.

13. Hammer, K. A.; Carson, C. F.; Riley, T. V. (1999). Antimicrobial activity of essential oils and other plant extracts. J. Appl. Microbiol., 86, 985-990.

14. Khajeh, M.; Yamini, Y.; Sefidkon, F.; Bahramifar, N. (2004). Comparison of essential oil composition of Carum copticum obtained by supercritical carbon dioxide extraction and hydrodistillation methods. Food Chem., 86, 587-591.

15. Kim, J.; Marshall, M. R.; Wei, C. (1995). Antimicrobial activity of some essential oil components against five foodborne pathogens. J. Agric. Food Chem., 43, 2839-2845.

16. Lambert, R. J. W.; Skandamis, P. N.; Coote, P.; Nychas, G. J. E. (2001). A study of the minimum inhibitory concentration and mode of action of oregano essential oil, thymol and carvacrol. J. Appl. Microbiol., 91, 453462.

17. Lucchesi, M. E.; Chemat, F.; Smadja, J. (2004). Solvent-free microwave extraction of essential oil from aromatic herbs: comparison with conventional hydro-distillation. J. Chromat. A, 1043, 323-327.

18. Marino, M.; Bersani, C. Comi, G. (2001). Impedance measurement to study antimicrobial activity of essential oils from Lamiaceae and Compositae. Int. J. Food Microbiol., 67, 187-195.

19. Mastelic, J.; Jerkovic, I. (2003). Gas chromatography-mass spectrometry analysis of free and glycoconjugated aroma compounds of seasonally collected Satureja montana. Food Chem., 80, 135-140.

20. Omidbeigy, M.; Barzegar, M.; Hamidi, Z.; Naghdibadi, H. (2007). Antifungal activity of thyme, summer savory and clove essential oils against Aspergillus flavus in liquid medium and tomato paste. Food Control, 18, 1518-1523.

21. Rezvanpanah, Sh.; Rezaei, K.; Razavi, S.H.; Moini, S. (2008). Use of microwave-assisted hydrodistillation to extract the essential oils from Satureja hortensis and Satureja montana. Food Sci. Technol. Res., 14, 311-318. 
Rezvanpanah, S. et al.

22. Sefidkon, F.; Abbasi, Kh.; Bakhshi, Gh. (2006). Influence of drying and extraction methods on yield and chemical composition of the essential oil of Satureja hortensis. Food Chem., 99, 19-23.

23. Sefidkon, F.; Jamzad, Z. (2005). Chemical composition of essential oil of three Iranian Satureja species (S. mutica, S. macrantha and $S$. intermedia. Food Chem., 91, 1-4.

24. Sivropoulou, A.; Papanikolaou, E.; Nikolaou, C.; Kokkini, S.; Lanaras, T.; Arsenakis, M. (1996). Antimicrobial and cytotoxic activities of Origanum essential oils. J. Agric. Food Chem., 44, 1202-1205.

25. Skocibusic, M.; Bezic, N.; Dunkic, V. (2006). Phytochemical composition and antimicrobial activities of the essential oils from Satureja subspicata vis. growing in Croatia. Food Chem., 96, 20-28.

26. Solomakos, N.; Govaris, A.; Koidis, P.; Botsoglou, N. (2007). The antimicrobial effect of thyme essential oil, nisin and their combination
Antibacterial properties of the essential oils from summer savory

against Listeria monocytogen in minced beef during refrigerated storage. Food Microb., 25, 120-127.

27. 27. Tukmechi, A.; Ownagh, A.; Mohebbat, A. (2010). In vitro antibacterial activities of ethanol extract of Iranian propolis (EEIP) against fish pathogenic bacteria (Aeromonas hydrophila, Yersinia ruckeri and Streptococcus iniae). Brazilian Journal of Microbiology, 41, 10861092.

28. Venskutonis, P. R. (1997). Effect of drying on the volatile constituent of thyme (Thymus vulgaris L.) and sage (Salvia officinalis L.). Food Chem., 59, 219-227.

29. Walsh, S.E.; Maillard, J.Y.; Russell, A.D.; Catrenich, C.E.; Charbonneau, D.L.; Bartolo, R.G. (2003). Activity and mechanism of action of slective biocidal agents on Gram-positive and -negative bacteria. J. Appl. Microbiol., 94, 240-247. 